\title{
OBITUARY
}

\section{William Halliburton McMullen}

William Halliburton McMullen was born on July 19, 1879, the son of a South London general practitioner, Dr. William McMullen. He was educated at the City of London School and King's College, London, where as a medical student he won first and second year scholarships, and was assistant demonstrator of ophthalmology and prosector. He continued his clinical work at King's College Hospital, qualifying in 1898 and taking his M.B., B.S., with Honours in 1900 . He held the posts of junior and senior house surgeon and took the F.R.C.S. (England) in 1900. He had now become interested in ophthalmology and became house surgeon at the Royal Westminster Ophthalmic Hospital, and was later appointed pathologist and curator. At almost the same time he became assistant ophthalmic surgeon to the Miller General Hospital and shortly afterwards, in 1906, assistant surgeon to the Royal Westminster Ophthalmic Hospital. From this time his career as an ophthalmic surgeon really began. He was for 8 years ophthalmic surgeon to the Hospital for Sick Children, Great Ormond Street, and for 4 years to the Royal Northern Hospital. During the 1914-1918 war he was ophthalmic specialist to the Central London Recruitment Depot, and in 1918 was awarded the O.B.E. In 1929 he was appointed honorary ophthalmic surgeon to Charing Cross Hospital. He maintained his connexion with the Royal Westminster Ophthalmic Hospital, wherein he was senior surgeon from 1927-1936, and when he retired from the staff he still maintained contact through the House Committee. He was President of the Section of Ophthalmology of the Royal Society of Medicine in 1937-1938, and also a Vice-President of the Ophthalmological Society of the United Kingdom.

In 1936 he retired from his active hospital work at the age of 60, but in 1939 he took up an appointment with the Emergency Medical Service. After 1945 he continued to take a great interest in ophthalmology and was an original member of the Faculty of Ophthalmologists. During his career he contributed many papers to the literature.

He was a man of most distinguished appearance, which the early whitening of his hair tended to enhance. Very quiet and reserved in manner, he yet had an authority which all respected. He was a very skilful, painstaking surgeon and an acute diagnostician, and his learning and experience were always at the service of his assistants and colleagues. He was beloved by his patients, with whom he was ever kind and gentle, reassuring them by his calm, quiet manner. He was a very competent artist in landscape work, both with pencil and in water-colour, and derived much pleasure from this, though he was very modest about it and could not be persuaded to exhibit. Those who saw his work, however, had the highest praise for it. He was fond of a game of golf, and up to 1939 was a member of Oxhey Golf Club, where he would sometimes entertain his friends.

In 1906 he married Miss Kate Constance Higgins, who survives him with three sons, and to them the sympathy of all his many friends, ophthalmologists and others, will go out. 